$\xi=-$ 圆

\title{
Evaluation of Rheological Behavior of Bitumen Modified with Nano Copper Oxide
}

\author{
G.H. Shafabakhsh ${ }^{1}$, S.R.Sajadib ${ }^{2}$ \\ ${ }^{I}$ Professor, Faculty of Civil Engineering, Semnan University, Semnan, I. R. Iran \\ ${ }^{2}$ Phd Student, Faculty of Civil Engineering, Semnan University, Semnan, I. R. Iran \\ * Corresponding author: E-mail address: Ghshafabakhsh@semnan.ac.ir
}

\begin{abstract}
Nowadays, one of the most challenging problems facing civil and transportation engineers, which consumes plenty of budgets (causes large amount of cost) for maintenance of asphalt roads, is asphalt destructions. Lots of efforts are done in order to increase the resistance and life span of asphalt, including development of bitumen properties. Bitumen is used broadly in road construction due to its appropriate properties; however, it has some major deficiencies which may lead to destructions of asphalt pavements. Therefore different bitumen modifications are implemented to achieve desired properties for different objectives, including (Such as) using rubber powder, waste materials, various polymers, etc. Recently, researchers are turning to nanotechnology to improve bitumen properties. Conducted studies on this topic (conducted research in this field) show that using modified bitumen by nanomaterial, increases the capacity of the pavement's load bearing and decreases probable cracks due to fatigue during the operation life of the pavement. In this study, Nano Copper Oxide is used to develop rheological properties of bitumen. Nanoparticles have been added to bitumen with amount of 2.5, 3 and 5 percent and then Dynamic Shear Rheometer (DSR) and Bending Beam Rheometer (BBR) experiments have been conducted to investigate the effects of using nanoparticles in pure bitumen. Results show that adding Copper Oxide nanoparticles to bitumen improves the performance of base bitumen, especially at middle and low temperatures.
\end{abstract}

Keywords: Nano Copper Oxide, Bitumen Modification, Rutting, Dynamic Shear Rheometer, Bending Beam Rheometer.

\section{Introduction}

Asphalt is now the first choice for highway construction for its various advantages like: smoothness, easiness, short period of construction and simple maintenance. [1] With the rapid development of transportation systems and therefore increase of loading and passing traffic, Asphalt's usage is getting broad and more serious.

Fracture in low temperature and fluidity in high temperature respectively lead to cracks in pavement in low temperature and rutting in high temperature, which drops the quality and

pavement performance down. Rutting creates permanent deformation, so in any weather conditions, especially hot weather, it is considered as one of the major destruction mechanisms in asphalt pavements, which can decrease the duration of service of pavement and also hydroplaning when

water is trapped in cracks. Permanent deformations in top layers of asphalt grows when traffic load and wheel pressure increase. [2]

Performance, serviceability and durability of pavements depend on conjunction and adherence between bitumen and surface of aggregate in different conditions and the conjunction between bitumen and surfaces of aggregates depends on their physical and chemical properties. [3]

Destructions happened during operation life of pavement are mainly including rutting, permanent deformations, and cracks due to fatigue. Inasmuch as treating and reconstruction of such deficiencies are costly, preventing these phenomena are a cheaper strategy. One of the approaches of prevention from destruction is modification of bitumen properties. Researchers have used different methods such as making use of various polymers. Adding modifiers like nanomaterials to improve performance of the bitumen and asphalt mixture is getting popular in recent years. Nanocomposite is one of the most popular materials discovered for developing the properties of bitumen and asphalt mixture. [4] Nanotechnology includes techniques, setups and systems related to the nano scale. Nanotechnology is widely used in development of new generation of materials to improve the macroscopic properties of them with more satisfying performance. This technology is providing accessibility to smallest particles in civil engineering and is used in cases in which the dimensions of materials are in the range of 1 to 100 nanometers at least for one of the material dimensions. [5]

Bitumen modifiers are mainly used to develop the duration and performance of asphalt mixture when pure bitumen cannot meet certain requirements in tough conditions. Different amounts and mixtures are used for enhancing the resistance against permanent deformations, fatigue cracks, cracks created in low temperature, humidity damages, and aging. [6]

In recent years, using nanomaterials for strengthening common materials in pavement have gained popularity, due to its high efficiency, being multipurpose, and long term performance. Exclusive mechanical and rheological properties of nanomaterials are useful for designing and manufacturing pavement materials. Dispersion of nanoparticles and chemical compatibility with bitumen matrix are main challenges in development of bitumen nanocomposite materials. Development of nanocomposite materials mainly depends on betterment of the adherent of nanocomposite/bitumen 
matrix and homogeneous distribution of nanoparticles in bitumen matrix. [7]

\section{Research History}

There has been a great deal of (extensive) research in applications of nanotechnology in asphalt mixture, some of which are reviewed here:

Ghaffarpoor Jahromi investigated the effect of nano-clay upon rheological properties of bitumen. Experiments conducted on bitumen samples showed (demonstrated) that bitumen modifier improves (causes a growth of) the stiffness and resistance against aging. It is also concluded that elastic properties of modified bitumen by nano-clay are much more than base bitumen. [8]

Assessment of properties of unaged bitumen modified with carbon nanoparticles which was carried out by Amirkhanian et al. showed that adding carbon nanoparticles increases the viscosity of bitumen and it also has a remarkable effect on bitumen performance degree. This research specified that bitumen containing $1 \%$ of nanoparticles has one more grade of the PG degree. [9]

Mobaraki et al. investigated rheology of the modified bitumen with Aluminum Oxide nanoparticles and Acrylate Styrene Acrylonhrtilrei (ASA) polymer. Modified bitumen with 3, 5 and 7 percent of each modifier (Nano Aluminum Oxide and ASA) were assessed. The results of the tests pointed out that the viscosity of the modified bitumen increased with more amount of modifiers besides all the values of viscosity were in particular range. Base bitumen had the least amount of $\mathrm{G}^{*}$ and $\mathrm{G}^{*} / \sin \delta$ compared with modified bitumen and also the modified bitumen with $5 \%$ of Nano Aluminum Oxide had the best functionality of resistance against rutting among all modified samples. Using Aluminum Oxide nanoparticles generally displayed better results compared to using ASA polymer. [10]

Sadeghnejhad et al. studied physical and rheological properties of modified bitumen with various nanomaterials. Results indicated that adding $1.2 \%$ of Nano Silica and $0.9 \%$ of Nano Titanium Oxide into bitumen leads to an upper resilience point compared to base bitumen. Also adding $1.2 \%$ of Nano Silica and $0.9 \%$ of Nano Titanium Oxide into bitumen brought about the best result for shear modulus in 60-70 bitumen. The shear modulus of bitumen with $1.2 \%$ of Nano Silica in comparison with bitumen with $0.9 \%$ of Nano Titanium Oxide, is $10 \%$ greater. [11]

Moghaddasnejhad et al. conducted investigations on the effects of using Nano Calcium Carbonate on dynamic behavior of asphalt mixture. Results identified that mixture made with Nano Calcium Carbonate in comparison with the control mixture, has less potential for rutting and also increasing the amount of Nano Calcium Carbonate up to $4 \%$ decreases the potential of rutting. Moreover, the results reveals that using Nano Calcium Carbonate in asphalt mixture, boosts the fatigue duration, in $15^{\circ} \mathrm{C}$ temperature, by $41.4 \%$ and $55.8 \%$ respectively for mixtures with $2 \%$ and $4 \%$ of Nano Calcium Carbonate [12].

Besides, various researches focused on using nanoparticles in bitumen and asphalt mixture [13-15]; however, there is not much information about the effects of Nano Copper Oxide on bitumen. Therefore, in this research Nano Copper Oxide is used as modifier in pure bitumen and its effects are investigated.

\section{Research Necessity}

Bitumen forms a small amount of volume and weight of asphalt mixture, but it plays an important role in performance of pavement layers. Even though bitumen has various applications and useful properties in road construction industries, it has major deficiencies which cause various damage in asphalt pavements. Among its deficiencies are high sensitivity to temperature of bitumen and asphalt pavement as a result, excessive softness in high temperatures which leads to rutting, low elasticity in low temperatures which leads to temperature asphalt cracks, and viscosity of bitumen that forms permanent and irreversible deformations in asphalt pavement and pavement fatigue under heavy traffic and load. Considering these problems, researchers investigate modifying the rheological properties of bitumen. One of the novel methods in this area, is modifying the bitumen using nanoparticles. Nanoparticles, due to capability of offering completely (totally) new (different) or developed properties, based on particular characteristics (size, distribution, constitution, phase, etc.) in comparison with massive sizes of the same particles, and also minute size of particles $(1-100 \mathrm{Nm})$ and having very large specific surface, can have significant effects on development of rheological properties of bitumen and asphalt pavement, though they are added in small percent as modifiers to bitumen.

Although nanotechnology is recently used in modifying and developing properties of bitumen and asphalt mixtures, significant researches are conducted in recent years on nanomaterials performance in asphalt pavements. However, considering the wide range of nanoparticles that can be used in structure industry and infrastructures, the effects of a good many of these particles in bitumen and asphalt mixture have not been investigated yet. One of these materials is Nano Copper Oxide which is investigated in this study as bitumen modifier.

\section{Research Method}

This research is conducted aiming at modification of rheological properties of bitumen, and the modifier was Nano Copper Oxide. Nanoparticles in 2, 3.5 and 5 percent were added to bitumen by high shear mixer and were aged for performance experiments. DSR and BBR experiments were conducted for evaluating rheological properties of modified bitumen with and without aging and the corresponding results were compared.

\subsection{Materials}

Materials used in these experiments consisted of bitumen and Copper Oxide nanoparticles. Properties of each material were obtained by different experiments and are reported below.

Bitumen

In this study, pure bitumen PG 64-16 made by Tehran Jay Oil Refining Co. was used, and its physical properties are listed in Table 1.

Table 1:. Pure bitumen properties

\begin{tabular}{|c|c|c|c|}
\hline \multicolumn{2}{|c|}{ Properties } & Values & Test standard \\
\hline \multicolumn{2}{|c|}{ Penetration $\left(25^{\circ} \mathrm{C}, 100 \mathrm{~g}, 5 \mathrm{~s}, 0.1 \mathrm{~mm}\right)$} & 64 & ASTM D5 \\
\hline \multicolumn{2}{|c|}{ Softening Point $\left({ }^{\circ} \mathrm{C}\right)$} & 49.8 & ASTM D36 \\
\hline \multicolumn{2}{|c|}{ Ductility $\left(\mathrm{cm}, 25^{\circ} \mathrm{C}\right)$} & $>100$ & ASTM D1754 \\
\hline \multicolumn{2}{|c|}{ Density $\left(60^{\circ} \mathrm{C}, \mathrm{kg} / \mathrm{m}^{3}\right)$} & 1018 & ASTM D70 \\
\hline \multirow{3}{*}{ Thin film oven test (TFOT) } & Mass change $(\%)$ & 0.003 & ASTM D6 \\
\hline & Penetration ratio $(\%)$ & 74.7 & ASTM D6 \\
\hline & Ductility $\left(25^{\circ} \mathrm{C}, \mathrm{cm}\right)$ & $>100$ & ASTM D113 \\
\hline
\end{tabular}

Copper Oxide Nanoparticles In order to modify bitumen, Copper

Oxide nanoparticles produced by US Research Nanomaterials Co. 
were used in this research. Properties of Copper Oxide nanoparticle are listed in Table 2. Figure 1 depicts FE-SEM image of this nanoparticle.

Table 2:. Nano Copper Oxide Properties

\begin{tabular}{|c|c|c|c|c|c|}
\hline Purity & Size of Particles & Specific Area & True Density & Shape & Color \\
\hline $99 \%$ & $40 \mathrm{~nm}$ & $20 \mathrm{~m}^{2} / \mathrm{gr}$ & $6.4 \mathrm{~g} / \mathrm{cm}^{3}$ & Approximately Spherical & Black \\
\hline
\end{tabular}

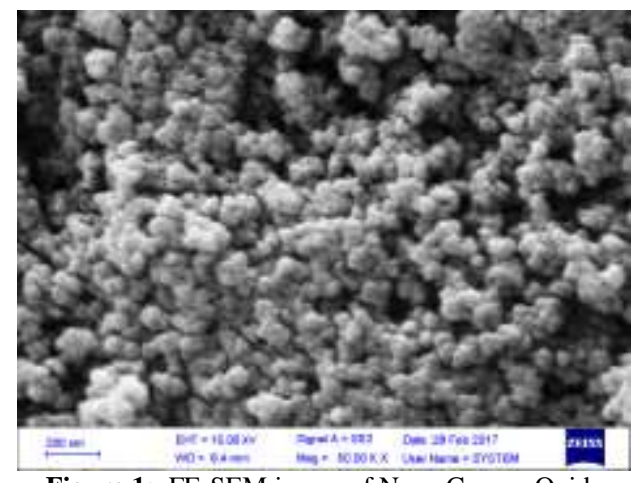

Figure 1:. FE-SEM image of Nano Copper Oxide

Preparation of Bitumen Samples

In this research (study), PG 64-16 pure bitumen were prepared and used for bitumen samples containing Nano Copper Oxide. Nano Copper Oxide was used as modifier in bitumen. Copper Oxide nanoparticles in 2.00, 3.50 and 5.00 percent were mixed with bitumen by high shear mixer in $160^{\circ} \mathrm{C}$ for 45 minutes with $4000 \mathrm{rpm}$, in order to obtain a homogeneous mixture of bitumen and nanoparticles.

\subsection{Experiments}

In this research, for evaluating modified bitumen, Rolling Thin Film Oven Test (RTFOT), Pressure Aging Vessel (PAV), Dynamic Shear Rheometer (DSR) and Bending Beam Rheometer (BBR) are used, instructions of which are explained below.

4.2.1. Aging Tests

Aging of modified bitumen are done by using test on effect of heat and air on thin film of moving bitumen (Rolling Thin Film Oven Test, RTFOT) according to ASTM D1754 and Pressure Aging Vessel (PAV) test according to ASTM D6521. Test on effect of heat and air on thin film of moving bitumen, simulates short term aging in process of mixing with aggregate, while Pressure Aging Vessel test simulates long term aging in service duration.

Dynamic Shear Rheometer Test

The behavior of bitumen is a function of temperature and loading time and an appropriate test for evaluating such materials should be able to evaluate both mentioned(two) parameters. One of the advanced and widespread instruments for this aim, is Dynamic Shear Rheometer. By using this test one can measure fundamental rheological properties of bitumen including shear complex modulus $\mathrm{G}^{*}$ and phase angle $\delta$ in any temperature. These two parameters describe elastic and viscos behavior of bitumen. Shear complex modulus is a resistance criteria against deformation under shear stress cycles, which consists of two parts: elastic (reversible) and viscos (irreversible). Phase angle is a criteria of elastic to viscos deformation ratio. These two parameters are severely sensitive to temperature and loading frequency. In high temperatures, bitumen is similar to viscos fluids which are not able to return to their initial states; in contrary, in low temperatures it (bitumen) behaves like elastic materials which return to their initial state after unloading.

Dynamic Shear Rheometer (DSR) test was conducted on bitumen samples, for determining viscoelastic behavior, according to ASTM D-7175. In this test, the value of dynamic shear complex modulus $\left(\mathrm{G}^{*}\right)$ and phase angle $(\delta)$ of the tested bitumen are measured according to equations (1) and (2). By measuring the com- plex modulus in bitumen materials, the value of total complex shear modulus as well as elastic and viscos parts are evaluated. Phase angle is time lag between the applied shear stress and the result shear strain in degrees. $G^{*}$ is the total shear modulus, $\delta$ is phase angle in degrees, $\square$ max is the maximum of applied shear stress, $\gamma \max$ is the maximum shear strain, $\mathrm{t}$ is the time lag in seconds and $\mathrm{f}$ is the loading frequency $(1.59 \mathrm{~Hz})[16]$.

$\mathrm{G}^{*}=\max / \gamma \max$

$\delta=360 \times \mathrm{t} \times \mathrm{f}$

Permanent deformation is controlled by limiting the value of $\mathrm{G}^{*} / \mathrm{sin} \delta$ in test's temperature. The allowable values are $1.0 \mathrm{kPa}$ (for unaged bitumen) and $2.2 \mathrm{kPa}$ (for aged bitumen after RTFO test). Cracks due to fatigue are controlled to values less than 5000 $\mathrm{kPa}$ by limiting $\mathrm{G}^{*} \times \sin \delta$ (for aged bitumen by PAV). This method is suitable for temperatures between $5^{\circ} \mathrm{C}$ to $85^{\circ} \mathrm{C}$ in which the value of $\mathrm{G}^{*}$ is between 0.1 to $10000 \mathrm{kPa}$ [17].

Bending Beam Rheometer Test

Bending Beam Rheometer (BBR) test is used for determining the low temperature efficiency of bitumen that is aged by PAV. This test is conducted according to AASHTO T313. Parameters used for analyzing the results include creep stiffness $S(t)$, the maximum of which is $300 \mathrm{MPa}$, and $\mathrm{m}$ value (the slope of stiffness graph versus time), which its minimum is 0.300 . They are determined with BBR software [18].

\section{Analysis and Results of Tests}

Nano Copper Oxide was added to bitumen in 2, 3.5 and 5 percent of bitumen weight and rheological properties of modified bitumen were investigated. The reason for limiting the percentages up to $5 \%$ is that more usage amounts are not economically efficient.

The main goal of this research, besides investigating the performance of modified bitumen with Nano Copper Oxide, is to determine if there is any positive effect on the performance of pure bitumen PG 64-16, in low and high temperatures, because of using these nanoparticles as modifier

To this aim, Dynamic Shear Rheometer and Bending Beam Rheometer tests were conducted on pure and modified bitumen samples, under unaged, short term aged and long term aged circumstances.

\subsection{DSR Test Results}

$\mathrm{G}^{*} / \sin \delta$ is obtained from Dynamic Shear Rheometer test as measurement for evaluating of bitumen resistance against rutting. Larger values of $G^{*} / \sin \delta$ means enhancement in bitumen resistance against permanent deformations and rutting. Figure 2 illustrates $\mathrm{G}^{*} / \sin \delta$ resulted from DSR test, for pure bitumen and modified bitumen with Copper Oxide nanoparticles in 2, 3.5 and 5 percentages, for unaged bitumen, in $64^{\circ} \mathrm{C}$ and $70^{\circ} \mathrm{C}$. 


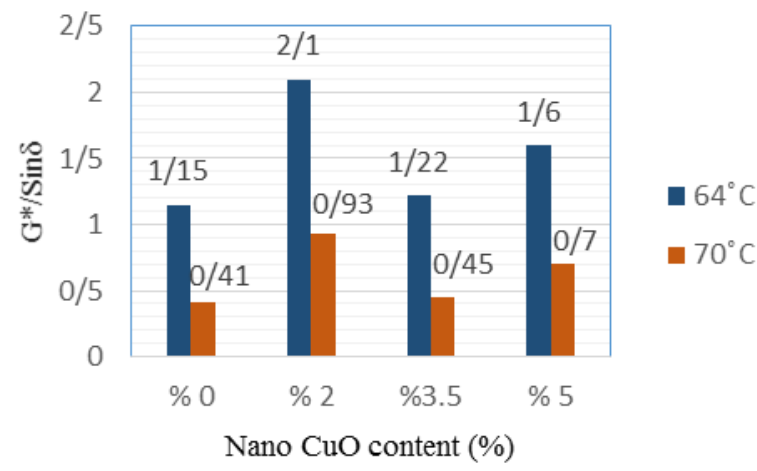

Figure 2:. Values of rutting measurements versus percentages of Nano Copper Oxide in modified bitumen without aging (unaged bitumen)

$\mathrm{G}^{*} / \sin \delta$ is more than $1.0 \mathrm{kPa}$ for all modified bitumen, which means using Copper Oxide nanoparticles for modifying bitumen, did not lead to decline in the performance grade of base bitumen. Results of this test in $64^{\circ} \mathrm{C}$ show that adding Nano Copper Oxide to bitumen increases the $\mathrm{G}^{*} / \sin \delta$ value. Among modified bitumen samples, the one with 2 percent of Nano Copper Oxide had the maximum increase, which was $82.6 \%$. This explins that Copper Oxide nanoparticles enhance stiffness and also stability of bitumen against deformation and rutting, in $64^{\circ} \mathrm{C}$.

Test was also done in $70^{\circ} \mathrm{C}$ temperature for determining the effect of adding Copper Oxide nanoparticles on development of bitumen performance in higher temperatures. As can be seen in figure 2, none of modified bitumen in $70^{\circ} \mathrm{C}$ has $\mathrm{G}^{*} / \sin \delta$ parameter greater than $1.0 \mathrm{kPa}$. This shows that adding Nano Copper Oxide to bitumen cannot develop performance of bitumen PG 64-16 in high temperature $\left(70^{\circ} \mathrm{C}\right)$.

In order to study the effect of short term aging (RTFO) of bitumen on its rutting measurement, base bitumen and modified bitumen aged by RTFO instrument, and then DSR test was conducted to evaluate properties of bitumen modified and aged by RTFO. Figure 3 displays $G^{*} / \sin \delta$ values resulted from DSR test for short term aged bitumen. These results show that rutting measurement for modified bitumen in $64^{\circ} \mathrm{C}$ is above $2.2 \mathrm{kPa}$ which is more than sharp requirements. This test was also conducted in $70^{\circ} \mathrm{C}$, but the results were not in sharp requirement range $\left(\mathrm{G}^{*} / \sin \delta>2.2 \mathrm{kPa}\right)$. Considering total set of results obtained from DSR test for modified bitumen which were unaged and aged by RTFO, one can conclude that modified bitumen with Nano Copper Oxide develops the rutting measurement $\left(\mathrm{G}^{*} / \sin \delta\right)$ of pure bitumen PG $64-16$ in its performance temperature $\left(64^{\circ} \mathrm{C}\right)$, but does not lead to development of base bitumen in high temperature $\left(70^{\circ} \mathrm{C}\right)$.

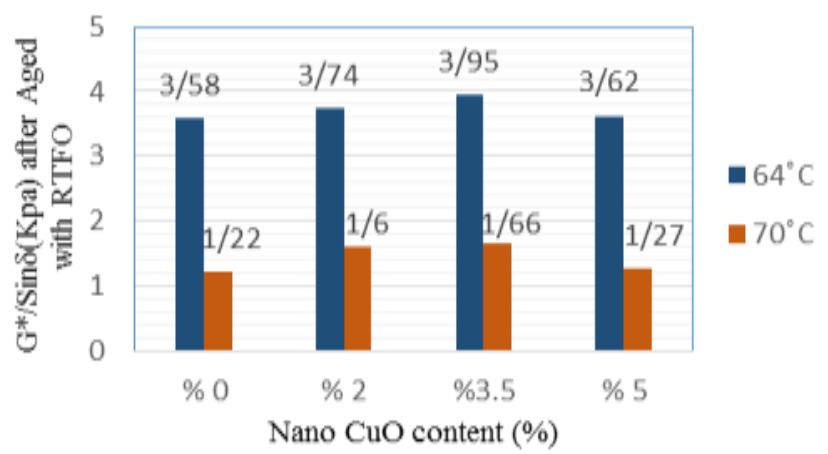

Figure 3:. Values of rutting measurement versus percentages of Nano Copper Oxide in modified bitumen with short term aging

Bending Beam Rheometer test was also conducted according to AASHTO T315, to evaluate dynamic viscoelastic properties $\left(\mathrm{G}^{*}\right.$, $\delta$ ) of modified bitumen with long term aging (PAV) in middle temperature. Sharp researchers defined a parameter as $G^{*} \times \sin \delta \leq$ $5000 \mathrm{kPa}$ to determine performance of bitumen in middle tem- peratures. This parameter investigates the effect of fatigue destruction which generally is one of the important pavement damages in moderate temperatures. Results of $\mathrm{G}^{*} \times \sin \delta$ obtained from DSR test on pure and modified bitumen samples are shown in Figure 4. A total descending manner in $\mathrm{G}^{*} \times \sin \delta$ parameter can be observed because of increasing Nano Copper Oxide in base bitumen which shows that rise in the amount of Nano Copper Oxide in bitumen causes improvement in fatigue parameter in modified bitumen and brings about better performance in middle temperature.

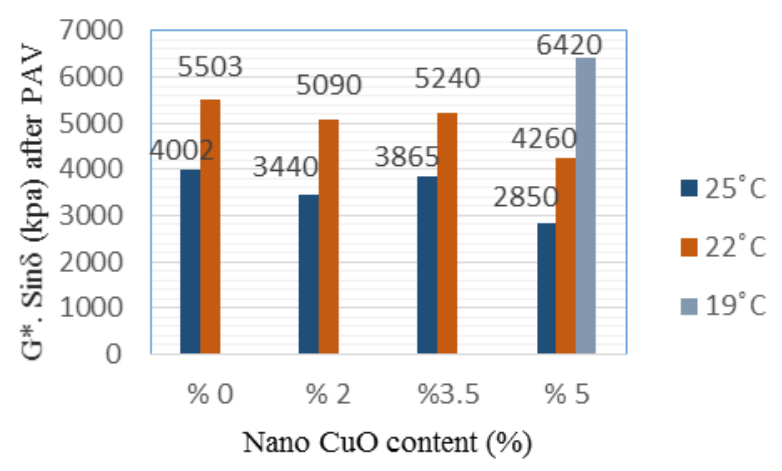

Figure 4:. Values of fatigue parameter versus percentage of Nano Copper Oxide in modified bitumen with long term aging

According to Sharp, the value of fatigue parameter $\mathrm{G}^{*} \times \sin \delta$ for pure bitumen PG 64-16 in temperature of $28^{\circ} \mathrm{C}$ should be less than $5000 \mathrm{kPa}$. (The results of the test for temperature of $28^{\circ} \mathrm{C}$ was very smaller than $5000 \mathrm{kPa}$. So only the results for $25^{\circ} \mathrm{C}$ and beyond that are showed.) From the results of DSR test one can observe that the value of fatigue parameter in $28^{\circ} \mathrm{C}$ for modified bitumen with Nano Copper Oxide is very smaller than $5000 \mathrm{kPa}$ and this fact holds even for $25^{\circ} \mathrm{C}$, which notifies better performance and also elastic behavior of modified bitumen with nanoparticles. Moreover, the elastic behavior of modified bitumen with $5 \%$ nanoparticles up to $22^{\circ} \mathrm{C}$, is in Sharp requirement range which shows that modified bitumen with 5\% Nano Copper Oxide has the best fatigue parameter performance among bitumen samples.

\subsection{BBR Test Results}

Bending Beam Rheometer test was conducted in temperatures $6^{\circ} \mathrm{C}$ and $-12^{\circ} \mathrm{C}$ and values of $\mathrm{S}(\mathrm{t})$ and $\mathrm{m}$ for pure and modified bitumen were evaluated in these temperatures. In bitumen, if the $\mathrm{m}$ value is greater than 0.300 and the value of creep stiffness is less than $300 \mathrm{MPa}$, its performance in low temperatures is better contraction cracks are prevented. The greatest $m$ value is desired because when the temperature falls, pavement begins to contract and bitumen as a material with lower stiffness, responds to this phenomenon. The decreased stiffness leads to smaller tensile stresses in bitumen and the probability of low temperature cracks get lower.

According to Sharp, for PG 64-16 bitumen in temperature $-6^{\circ} \mathrm{C}$, the value of $\mathrm{S}(\mathrm{t})$ should be less than $300 \mathrm{MPa}$ and $\mathrm{m}$ value should be greater than 0.300. $\mathrm{S}(\mathrm{t})$ results obtained from Bending Beam Rheometer test are shown in Figure 5. Based on these results, creep stiffness $\mathrm{S}(\mathrm{t})$ of all bitumen samples in temperatures $-6^{\circ} \mathrm{C}$ and $-12^{\circ} \mathrm{C}$ are in desired range (less than $300 \mathrm{kPa}$ ). However, $\mathrm{m}$ values (Figure 6) only for temperature of $-6^{\circ} \mathrm{C}$ for all bitumen samples are in desired range and in $-12^{\circ} \mathrm{C}$, this value just for modified bitumen with 5\% Nano Copper Oxide is above 0.300 . 


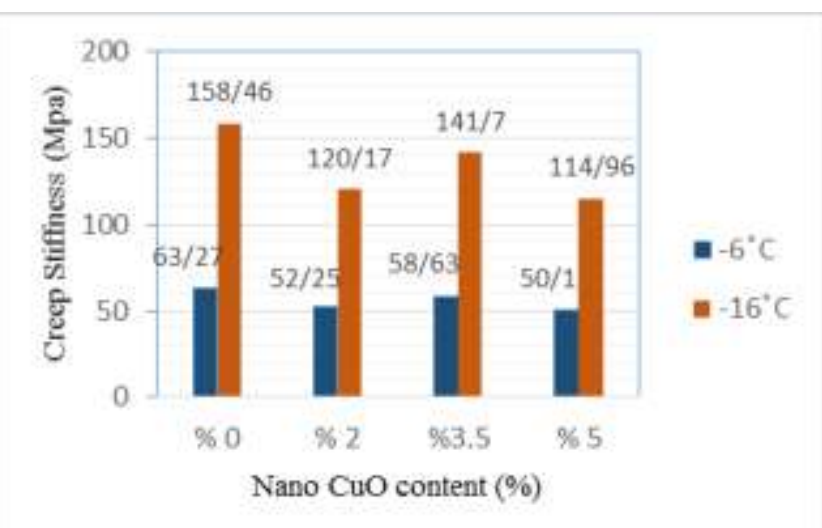

Figure 5:. The values of creep stiffness $\mathrm{S}(\mathrm{t})$ versus percentage of Nano Copper Oxide in modified bitumen with long term aging

This result shows that bitumen with $5 \%$ nanoparticles is suitable to prevent cracks in low temperature and do not undergo thermal stress in $-12^{\circ} \mathrm{C}$. In other words, although by increasing the nanomaterial resistance against cracking in low temperatures for other samples of modified bitumen (2\% and $3.5 \%)$ improves and they show good elastic properties, only the bitumen sample with 5\% Nano Copper Oxide could develop the performance of the base bitumen and brought PG 64-16 bitumen to PG 64-22 bitumen performance grade.

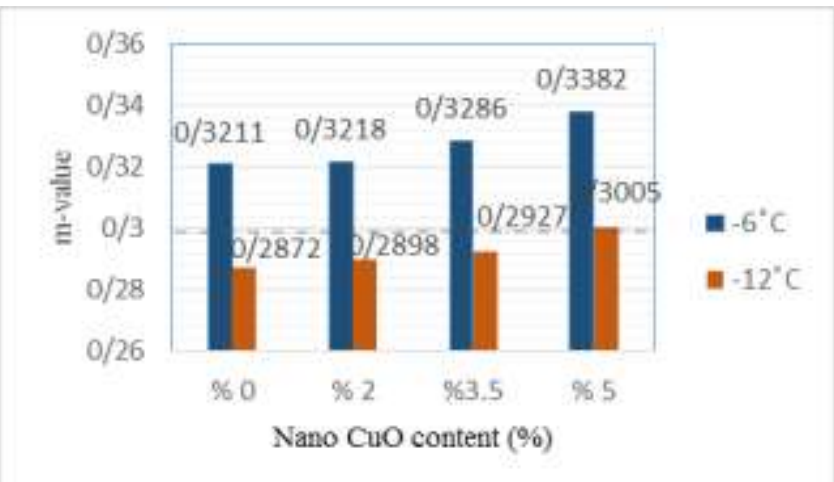

Figure 6:. $\mathrm{m}$ value versus percentage of Nano Copper Oxide in modified bitumen with long term aging

\section{Conclusion}

This research was conducted in order to investigate the effects of using Nano Copper Oxide as modifier in pure bitumen PG 6416. The conclusions obtained from Dynamic Shear Rheometer (DSR) and Bending Beam Rheometer (BBR) tests for studying rheological properties of modified bitumen with 2, 3.5 and 5 percent of Nano Copper Oxide are as follows:

Results of DSR test for evaluating modified bitumen without aging and with short term aging (RTFO) in high temperature showed that in general by adding nanoparticles in bitumen, rutting measurement $\mathrm{G} * \sin \delta$ increases which means bitumen modified with nanoparticles are more resistant against rutting destruction and permanent deformations. Additionally, adding Nano Copper Oxide in pure bitumen develops the rutting measurement in its performance temperature grade $\left(64^{\circ} \mathrm{C}\right)$; However, it is not the same for higher temperature performance.

Results of DSR test in middle temperature and for modified bitumen which is long term aged (PAV) showed that by adding Nano Copper Oxide in pure bitumen, fatigue parameter $\mathrm{G}^{*} \times \sin \delta$ has a descending manner that leads to improvement of performance and enhancement in elastic behavior of bitumen in middle temperature. The best performance levels among bitumen samples were belonged to modified bitumen with $5 \%$ nanoparticles which in $28^{\circ} \mathrm{C}, 25^{\circ} \mathrm{C}$ and $22^{\circ} \mathrm{C}$ were in Sharp desired range.

Bending Beam Rheometer test determined that values of $\mathrm{S}(\mathrm{t})$ as well as $\mathrm{m}$ values for modified bitumen samples in $-6^{\circ} \mathrm{C}$ are placed in desired range of Sharp and rise in amount of nanoparticles improves $\mathrm{S}(\mathrm{t})$ (with descending manner) and $\mathrm{m}$ values (with ascending manner) in bitumen modified with Copper Oxide nanoparticles. Also the best results among bitumen samples were related to modified bitumen with 5\% Nano Copper Oxide that led to PG 6416 bitumen improvement into PG 64-22 bitumen performance grade.

Noting(considering) method and material used in this research, one can conclude that adding Nano Copper Oxide in pure bitumen PG 64-16 in amount of 5\% can develop the rutting measurement in high temperature as well as in its performance grade temperature $\left(64^{\circ} \mathrm{C}\right)$, and also improve fatigue parameter in middle temperature and gain acceptable resistance against cracks due to thermal stresses.

\section{References}

[1] Shi, Xingang, Liangcai Cai, Wei Xu, Jing Fan, and Xinhang Wang. "Effects of nano-silica and rock asphalt on rheological properties of modified bitumen", Construction and Building Materials, vol. 161, 2018, p. 705-714.

[2] Shafabakhsh, G. H., O. Jafari Ani, and M. Talebsafa. "Artificial neural network modeling (ANN) for predicting rutting performance of nano-modified hot-mix asphalt mixtures containing steel slag aggregates", Construction and Building Materials,vol. 85, 2015, p. 136-143.

[3] Omar, Hend Ali, Nur Izzi Md Yusoff, Halil Ceylan, Irman Abdul Rahman, Zainuddin Sajuri, Fauzan Mohd Jakarni, and Amiruddin Ismail. "Determining the water damage resistance of nano-clay modified bitumens using the indirect tensile strength and surface free energy methods", Construction and Building Materials, vol. 1672018 , p. 391-402.

[4] Shafabakhsh, G. H., S. M. Mirabdolazimi, and M. Sadeghnejad. "Evaluation the effect of nano-TiO2 on the rutting and fatigue behavior of asphalt mixtures", Construction and Building Materials, vol. 54 2014, p. 566-571.

[5] Jamshidi, Ali, Mohd Rosli Mohd Hasan, Hui Yao, Zhanping You, and Meor Othman Hamzah. "Characterization of the rate of change of rheological properties of nano-modified asphalt", Construction and Building Materials, vol. 98, 2015, p. 437-446.

[6] Bahia, Hussain U., D. I. Hanson, M. Zeng, H. Zhai, M. A. Khatri, and R. M. Anderson. Characterization of modified asphalt binders in superpave mix design. No. Project 9-10 FY'96. 2001.

[7] Khattak, Mohammad Jamal, Ahmed Khattab, and Hashim R. Rizvi. "Characterization of carbon nano-fiber modified hot mix asphalt mixtures", Construction and Building Materials, vol. 40, 2013, p.738-745.

[8] Jahromi, Saeed Ghaffarpour, and Ali Khodaii. "Effects of nanoclay on rheological properties of bitumen binder", Construction and Building Materials, vol. 23, no. 8 2009, p. 2894-2904.

[9] Amirkhanian, Armen N., Fei-Peng Xiao, and Serji N. Amirkhanian. "Characterization of unaged asphalt binder modified with carbon nanoparticles", International Journal of Pavement Research and Technology, vol. 4, no. 5 2011, p. 281-286.

[10] Mubaraki, Muhammad, Shaban Ismael Albrka Ali, Amiruddin Ismail, and Nur Izzi Md Yusoff. "Rheological Evaluation of Asphalt Cements Modified with ASA Polymer and Al2O3 Nanoparticles", Procedia engineering, vol. 143, 2016, p. 1276-1284.

[11] Sadeghnejad, Mostafa, and Gh Shafabakhsh. "Experimental Study on the Physical and Rheological Properties of Bitumen Modified with Different Nano Materials(Nano SiO2 \& Nano TiO2)", International Journal of Nanoscience and Nanotechnology. Vol. 13, no. 3 2017, p. 253-263.

[12] Moghadas Nejad, Fereidoon, Ehsan Geraee, and Ali Reza Azarhoosh. "The effect of nano calcium carbonate on the dynamic behaviour of asphalt concrete mixture", European Journal of Environmental and Civil Engineering, 2018, p. 1-10.

[13] Chen, Zihao, Henglong Zhang, Chongzheng Zhu, and Bin Zhao. "Rheological examination of aging in bitumen with inorganic nanoparticles and organic expanded vermiculite", Construction and Building Materials, vol. 101 2015, p. 884-891. 
[14] Ziari, Hasan, Amir Amini, Ahmad Goli, and Danial Mirzaeiyan "Predicting rutting performance of carbon nano tube (CNT) asphalt binders using regression models and neural networks", Construction and Building Materials, vol. 160, 2018, p.415-426.

[15] Gazizov R., Nagovitsyna T. A., Political manipulation of The Media (on the example of mass media of the republic of Tatarstan, Astra Salvensis - review of history and culture, No. 10, 2017, p. 11-16.

[16] Sadeghnejad, M., and Gh Shafabakhsh. "Estimation the fatigue number of stone mastic asphalt mixtures modified with nano $\mathrm{SiO} 2$ and nano TiO2", Journal of Rehabilitation in Civil Engineering, vol. 5, no. 1, 2017, p.17-32

[17] Husnutdinov D. H., Aydarova S. H., Sagdieva R. K., Mirzagitov R H., Tsaran A., Plotnikova H., Velikanova S. Information and Communication Tools for Tatar Language teaching, Astra Salvensis, Supplement No. 2, 2017, p. 15.

[18] Harrigan, E. T., R. B. Leahy, and J. S. Youtcheff. Superpave manual of specifications, test methods and practices. SHRP-A-379, Strategic Highway Research Program, National Research Council, Washington, DC, 1994. 